\title{
A Longitudinal Study of Adolescents' Future Orientation (Time Perspective)
}

\author{
Gisela Trommsdorff, ${ }^{1}, 4$ Helmut Lamm, ${ }^{2}$ and Rolf W. Schmidt ${ }^{3}$
}

This longitudinal study was designed to test hypotheses concerning the influence of environmental changes in different groups (educational status; sex) of adolescents on their future orientation (FO). FO was measured through a freeresponse questionnaire on which the subjects indicated their hopes and fears (which were later categorized into various domains of life by independent judges). On a second questionnaire the subjects adjudged their present and future life in various given domains of life. The sample consisted of 24 male and 24 female adolescents, aged between 14.16 years at the time of the first measurement; the second measurement took place two years later. Half of the subjects of each sex were students at a Gymnasium (preparing for university study) at both times of measurement ("high social status"). The other half of the subjects of each sex were in their last year at the Hauptschule (continuation of elementa$r y$ education) at the first time of measurement, and had taken up employment (e.g., an apprenticeship) by the time of the second measurement ("low social

This study was conducted at the Sonderforschungsbereich 24, Sozial- und wirtschaftspsychulugische Entscheidungsforschung, Universitiat Mannheim (West Germany), and financed by the Deutsche Forschungsgemeinschaft, with support from the Government of Baden. Wurttemberg. The three authors have contributed equally to this article.

"Research Director, Sonderforschungsbereich 24, Universitat Mannheim: "Social conditions of future orientation" (X. 11). Received her Ph.D. from Universitat Mannheim. Major interests are judgnent and planning of small groups, adolescents, delinquents, and married couples.

${ }^{2}$ Professor of Psychology, Padugogische Hochschule, Cologne. Received his Ph.D. from Princeton University. Major interests are small group processes, negotiation, and justice.

${ }^{3}$ Tejching Assistant at the Hochschule für Verwaltungswissenschaft, Speyer. He graduated from Universitat Mannheim. Major interest is sociology of organizations.

-All correspondence should be addressed to Gisela Trommsdorf, Sonderforschungsbereich 24, Universität Mannheim. Mannheim, West Germany. 
status"). At the time of the second measurement relatively more hopes and fears were voiced in the domains of personal development and occupation than at the first measurement. Independent of time of measurement, low-status subjects voiced relatively more hopes and fears related to the occupational domain, and boys had a more extended FO than girls. Low-status subjects - as compared to high-status subjects as well as to their own judgments at the first measurement - believed to a greater extent that the materialization of their hopes and fears depended on themselves rather than on external forces. These results support the assumption that FO cannot be dealt with as a global concept and that FO can be modified by change in the external environments, such as entry into an occupation.

\section{INTRODUCTION}

The process of lifelong individual development is sometimes characterized by significant changes in the social and physical environment. This is especially true for adolescents. Adolescents stand at a point of their life cycle when they have to face major changes stemming from the transition of an adolescent's role into the role of an adult. In this period of transition, one of the most important events is entry into the occupational world. The present study examines whether changes in adolescents' role patterns occur in correspondence with the assessment of their personal and social future, and in what areas the outlook on the future is changed.

The way one conceives of one's future is related to goal setting, planning, decision making, and behavior (Lewin, 1948, 1951; Nuttin, 1964; Heckhausen, 1967; Raynor, 1974). According to one's future orientation, one may plan certain activities in order to adapt to expected changes in the social environment. These expected an experienced changes, in turn, may cause changes in one's conception of the future (cf. Trommsdorff, 1978).

If aspects of future orientation are affected by changing conditions in the person's environment, this should be especially true for such important events and changes as leaving school and entering into employment. The effect of anticipated and actual occupational socialization may broaden and extend one's future time orientation and change the affective meaning of anticipation in certain domains.

Future orientation refers to attitudes and judgments concerning one's future. Thus, future orientation has a cognitive and an affective (evaluative) component, which are to be analyzed according to specific content areas (e.g., personality, family, occupation (cf. Trommsdorff and Lamm, 1975)).

Future orientation here does not refer to one single variable such as extension, coherence, density, kinesis, realism, importance or predominance of the future (cf. Winnubst, 1975). In several studies only one aspect of future orienta- 
lion has been investigated, implying that it alone represents luture orientation (ci. LeShan, 1952; Teahan, 1958; Barabasz, 1970). ${ }^{5}$

Only recently Lessing $(1971,1972)$ differentiated between a private and a public future orientation. In their cross-cultural study of relationships among four dinensions of time (perspective, extension, location, kinesis) and two conlent areas (social and religious), Roberts and Greene (1971) found differences in time orientation which can only be interpreted against the background of content. This supports our skepticism against a glotal ise of the time concept and emphasis on one temporal aspect to the neglect of others; when studying differences between persons and changes in their future orientation, each relevant aspect of future orierstion should be empirically investigated in relation to its social and other determinants.

The aspects of future orientation to be analyzed here are (a) a contentstructural (density), (b) a temporal-structural (extension), (c) an affective (optimism-pessimism) and (d) an attributional component (internal-external control).

The term density refers to the number of events and circumstances which a person hopes for or fears in various domains of life (cf. Kastenbaum, 1961). This index is designed to measure the cognitive structuring of the future (which may be determined partly by an affective preoccupation with specific domains).

The length of the future time span will be termed extension (Wallace, 1956). It is defined by the event localized the farthest in the future among all the events (hopes and fears) mentioned by an individual. This index is one of the most widely ușed measurements in the literature on future time perspective and orientation. One of its shortcomings lies in the notion that people conceive of their future linearly (cf. Winnubst, 1975). Another problem is that future events such as one's retirement, have an "objectively" definable date of occurrence. This may cloud individual differences in extension.

Optimism is understood here as the hope for positive changes in the future (e.g., Teahan, 1958); accordingly, the variable will be operationalized as the positive difference between the evaluation of the future and the evaluation of the present (cf. Cantril, 1965). Likewise, a pessimistic attitude is represented by a negative difference. If the present is already satisfying, the future could not be much more positive on a scale with a fixed anchor point. Though subjective optimism for the future is still given, it cannot adequately be measured by scaling evaluations and drawing differences between the present and the future.

The above-mentioned three aspects of futur orientation are investigated in the following domains of life: (a) personality and self-actualization, (b) physical well-being and appearance, (c) family, and (d) occupation.

\footnotetext{
${ }^{3}$ A more extensive elaboration on future orientation and future time perspective can be found in Bergius (1957), Doob (1971), Fraisse (1957), Mönks (1967), Winnubst (1975), and Trommsdorif et al. (1978).
} 
In addition, an attributional component, belief in internal versus external control, will be assessed. Specificully, internal control means that a person believes that he himself (or herself) mainly determines and decides the course of events (the fulfilment of his or her hopes and fears), whereas external control of events means that a person sees the events as something he himself cannot influence (cf. Rotter, 1966; Jessor et al., 1968). The elaborated categories which have recently been developed in attribution theory (cf. Weiner, 1974) could not be included here, partly because these categories are construed for achievement situations.

\section{Hypotheses}

During adolescence the number of behavioral options increases; the "space of free movement" becomes larger (cf. Lewin, 1951). Also, the repertoire of perceptual and behavioral possibilities increases. Accordingly, the "psychological" future - and correspondingly the future time orientation - should expand and reach a higher level of reality, organization, and integration.

According to this assumption one could hypothesize that with increasing age more events are included in the future time orientation and that these events are localized in a (temporarily) more distant future; the future time orientation becomes "denser" and more extended. However, only a few empirical results support this supposition, at least in relation to the extension of future time perspective. Toban (1970) found a positive correlation between age and extension. Klineberg (1967), investigating normally adjusted adolescents, was able to show that the extension of future time perspective increased from childhood to adolescence. These authors probably measured both cognitive and motivational aspects of future time perspective. The subjects were asked to indicate the time when certain events would occur. However, at a purely cognitive level, escapist fantasies may induce a longer future time perspective in younger than in older children (cf. Lessing, 1972).

A long extension of the future orientation may imply an extremely optimistic view of the future, since wish and reality become interrelated. The positive correlation between optimism and future time perspective (extension) reported by Teahan (1958) supports this supposition. However, the increase in "rationality" (reality orientation) with growing age and experience should block a wishful-thinking optimism. On the other hand, differences in optimism may well reflect the experience of one's present and a realistic anticipation of one's future situation.

Adolescents represent a group which has to expect and to deal with significant changes. The experience of work should induce adolescents to redefine hopes and fears, expectations and planning for the future, in respect to occupational life. 
Whether this will be true for boys and girls is another question to be siudied. According to tradirional sex roles, females should conceive differently of their future than males. Females probably have less concern for the occupational than for the family domain as compared to males (cf. Brannigan and Tolor, 1971; Lehr, 1972; Lamm et al., 1976). Possibly, these traditional concerns may change by adoption to an occupational role.

The experience of work presumably influences not only the content. structural and time-structural aspects of future orientation but also its affective aspects of optimism and pessimism.

The working adolescent probably experiences more possibilities of internal (or self-) control of behavior which were previously unknown to him. The experience of an occupuional role could be iclated to an increase in independence or confidence in freedom of choice, and may thus induce a self-assured and optimistic view of the future. On the other hand, occupational experience can be disillusioning: the everyday routine, inability to cope with role requirements, and other stresses may induce a pessimistic view of one's occupational future.

Based on the above considerations, the following hypotheses will be tested:

Hypothesis I: (a) The future orientation of older adolescents includes more events (hopes/fears) in the domain of personal development and occupation than that of younger adolescents. (b) Working adolescents have relatively more hopes and fears connected with the occupational domain than adolescents in school. (c) Female adolescents have relatively more hopes and fears in the family domain than male adolescents.

Hypothesis II: (a) In most domains older adolescents have a more extended future orientation than younger adolescents. (b) Working adolescents have a longer future orientation in the occupational domain than adolescents in school.

Hypothesis III: (a) Older adolescents are more optimistic about the future than younger adolescents. (b) Working adolescents are more optimistic about the occupational future than adolescents in school.

Hypothesis $I V$ : Working adolescents evaluate their future as being more internally controlled than adolescents in school.

\section{METHOD}

\section{Subjects}

Data were collected from 24 male and 24 female secondary school students. Half had a Hauptschule education (a direct extension of the four-year elementary school) where, upnn graduation, one takes on a full-time job or an apprenticeship; and half had their edu. "ition at a Gymnasium, a school corresponding to a 
college preparatory American high school. The schools which the subjects visited were located in a West German industrial city (Mannheim). An open invitation for participation was posted in randomly chosen schools of these two types. Five Deutsche Mark were promised for each hour of participation.

From students who initially responded to the invitation, 50 "Gymnasiasten" and 50 "Hauptschuler" students were chosen at random, 25 females and 25 males in each group. The 50 Hauptschule students belonged to the lower class; the heads of their families had only Hauptschule education. The $50 \mathrm{Gym}$ nasium students belonged to the middle class. The head of family here had completed high school. These two groups also differed in level of income and occupational position of the head of family corresponding to their lower and middle class position. The adolescents questioned were between the ages of 14 . 16 at the time of the first measurement.

To obtain a second measurement, after two years, all 100 subjects received a written invitation to participate another time in a "related" investigation. We were able to obtain 48 respondents, 12 in each group (sex and school type). The adolescents of the Hauptschule were employed by the time of the second investigation, whereas those from the Gymnasium were still at school. Unfortunately, no control group could be obtained - matching the Hauptschule sample in education, age and sex - where subjects had not yet started to work. ${ }^{6}$ Thus we had to use the Gymnasium sample as a quasi-control group.

\section{Design}

A longitudinal study was designed to control for the effects of environmental changes on future orientation - here the effect of leaving school and entering into work life (as compared to staying in school).

The independent variables (factors) were Sex (factor A), Education (factor $B$ ), and Life Changes (first versus second measurement) (factor $C$ ), with two levels each. The number of respondents in each of the eight cells was 12. The factors were all "fixed."

\section{Future Orientation ${ }^{7}$}

The dependent variables were measured by a questionnaire which was the same for the first and second testing. Subjects completed the questionnaire individually.

"The first mcasurement took place in 1972 when no economic recession had as yet occurred and all Hauptschule graduates found an apprenticeship right away. It was thus impossible to find a control group of unemployed Hauptschule graduates.

'Future time perspective and orientation have been measured in several ways. Winnubst (1975) discusses the validity and reliability of most of the measurements used: free- 
Density. First subjects listed their hopes and then their fears (10 minutes each). Two independent judges later classified these hopes and fears into several eategories of personal and public life. We are unly interested here in the personal life data. Categories to classify concern of personal life were (a) personality and self-actualization, (b) physical well-being and appearance, (c) family, (d) occupa. tion. The two judges agreed in $83 \%$ of the cases.

The number of hopes and fears listed in each of the four categories, divided by the total number of hopes and fears listed by a subject, served as the index of density. These proportions had to be transformed with arc $\sin \sqrt{x}$ to permit analyses of variance (Winer, 1971 , pp. 227 fr.).

Of course, this index of density only measures part of the cognitive structure of future orientation. This measure reflects the preoccupation with specific areas of future development. The more different areas a person anticipates in his or her hopes and ieas, he smaller will te the proportion of concerns for one area (when the time for listing concerns is held constant). Thus, a high propor. tion of concerns for one area may indicate strong preoccupation with this area, but may not indicate a solid cognitive structure for the future as a whole. Thus, the ratio of concerns in a specific domain should be seen in relation to the ratio in olher domains. In the present study, we are primarily interested in comparing the ratio of concerns in selected domains between the first and second measurement for females and males of two different educational levels.

Extension. Extension in the four categories cited was measured as the maximal difference between the subject's estimated age at the occurrence of an event and actual age at present (cf. Wallace, 1956). The concern (hope/fear) expected to materialize last (as compared to all other concerns in a given category) defined the degree of extension in the future. These data were normally distributed so that no transformation was needed.

Of course, this index is problematic in several respects. The most extended concerns do not necessarily indicate an adequate cognitive structuring for the future, but may merely focus on "social-developmental milestones" or just be unrealistic (cf. Lessing, 1972); the listing of any event expected to occur in the distint future indicates an extended future orientation. Would it not be more valid to assess extension into the future by computing the mean score of differences between the estimated age of occurrence and actual age for each concern? We compared this latter measure with the measure using the most extended concern and found no differences between the two as regards the effects of sex and social class (Schmidt, 1973).

sesponse methods (e.g., "tell me a story," "story completion," "sentence completion," "TAT," "important events," "future events") and the scaling method (e.p., "Future Orientation Scale" by Zurcher et al, 1976). The present study uses the frec-response method (asking about hopes and fears in the fulure) and the sealing method technique developed by Cantril (1965). 
Internal Versus External Control. Each subject was asked for each hope or fear, whether its materialization would depend more on him/herself or on external circumstances. There were four answer categories $(a=$ "depends on me only"; $b=$ "depends more on me than on external circumstances"; $c=$ "depends more on external circumstances than on me"; $d=$ "depends only on external circumstances"). The proportion of hopes and fears which a subject categorized as internally controlled (category a or b), relative to the total number of hopes and fears, was calculated. Since these were proportions, the scores were transformed with $\arcsin \sqrt{ } x$.

Optimism-Pessimism. The subjects had to assess their present situation and their prospective situation in five years with regard to each of 10 given concerns (items).

For data analysis, the 10 concerns were condensed into four categories which were designed to correspond roughly to the four categories used for the density and extension measures. These four categories were (a) personality and self-actualization (e.g., "my inner satisfaction"); (b) physical well-being and appearance (e.g., "my health"); (c) family and interpersonal relations (e.g., "my personal relations within my family"); and occupation (e.g., "my financial situation").

The 11-point scale, adapted from Cantril (1965), runs from 0 ("worst con. ceivable situation") to 10 ("best conceivable situation"). The mean difference between the assessment of the future and of the present was calculated for each of these categories (positive difference $=$ optimism; negative difference $=$ pessimism). The distribution of the data was normal.

\section{RESULTS}

Tables I and II contain the means of the dependent variables and the sig. nificant $F$ values from the $2 \times 2 \times 2$ analyses of variance. ${ }^{8}$ Winer's (1971) "simple effects" $\left(F_{S}\right)$ were calculated to test for significance of difference between single cells, in the case of interactions. The degrees of freedom for these $F_{S}$ values are 1 and 44 .

\footnotetext{
The interested reader is referred to Lamm et al. (1976), where the results only of the first measurement (complete sample, $N=100$ ) are presented and discussed. The data of the present article are bused on responses of $S S(N=48)$ from both first and second measurements.
} 


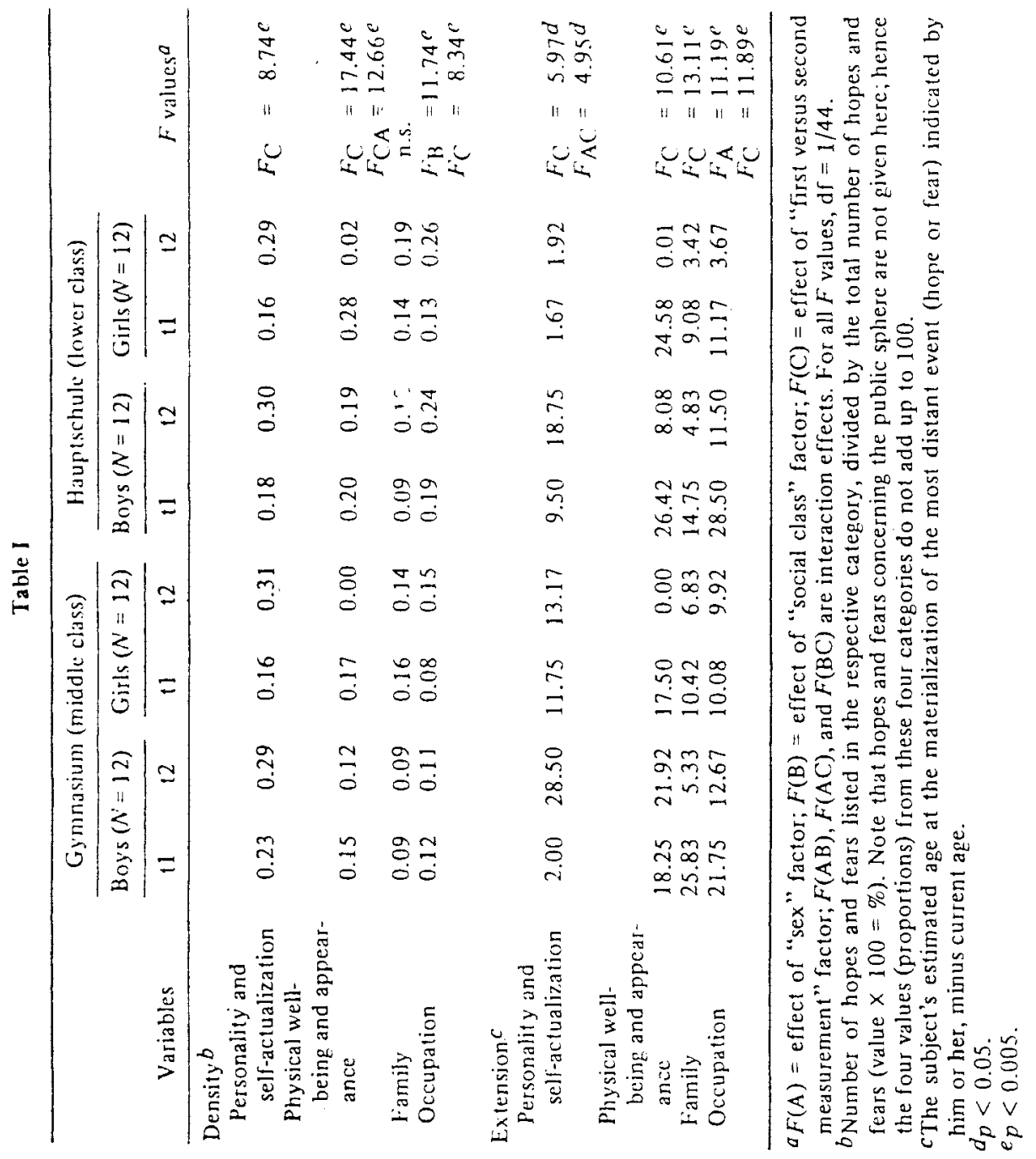




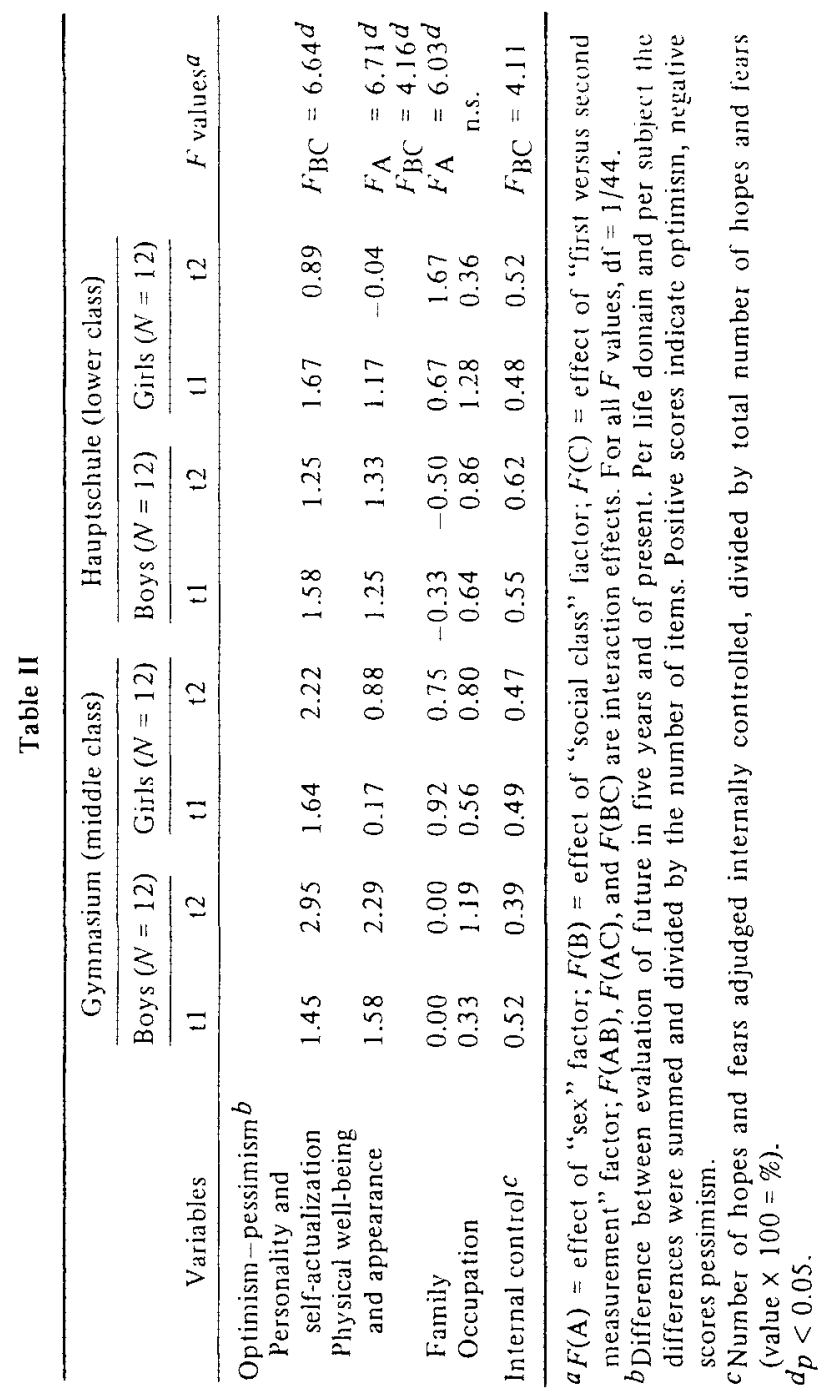




\section{Density'}

Hy'puthesis la was confirmed in the areas of "personality and self-actualization" $(p<0.005)$ and "occupation" $(p<0.005)$. Adolescents cited relatively more hopes and fears in this domain at the time of the second as compared to the lirst measurement.

Hypothesis Ib was also confirmed. The working adolescents cited relatively more events in the occupational sphere than the Gymnasium students, independent of the time of the measurement $(p<0.005)$.

Hypothesis Ic could not be confirmed; there were no significant differences in the family domain.

Not expected were the sex differences in the area "physical well-being and appearance"; girls cited fewer hopes and fears in this area at the second measurement than boys $(p<0.005)$.

\section{Extension}

Hypothesis Ila, which predicted a more extended future orientation in older adolescents, was supported only in the area "personality and self-actualization" $(p<0.05)$. Here the male adolescents had a more extended future orientation at the time of the second (as compared to the first) measurement $\left(F_{S}=21.80\right.$; $p<0.005)$. This difference was not significant for the girls. In all other categories the future orientation was shorter for all groups in the second measurement than in the first. Thus, hypothesis Ila was generally not confirmed.

Hypothesis Ilb could not be confirmed. Working adolescents did not show a more extended future orientation in the occupational domain than Gymnasium students. However, unexpected results concerned the role of sex: In both measurements males had a more extended future orientation in the occupational domain than females $(p<0.005)$. Also males extended their concerns for their personality and self-actualization more into the future than girls in the second measurement $(p<0.05)$. Furthermore, in the second measurement boys had a more extended future orientation for "physical well-being and appearance" than girls $(p<0.005)$.

\section{Optimism-Pessimism}

Hypothesis IIIa, which predicted greater optimism for older adolescents, could only be confirmed for certain content areas. The adolescents in the Gymnasium group were more optinistic at the second (than at the first) measurement, while adolescents with a Hauptschule education decreased their optimism in the areas of "personality and self-actualization" $\left(F_{S}=11.21 ; p<0.005\right)$ and 
of "physical well-being and appearance" $\left(F_{S}=5.91: p<0.05\right)$. Hypothesis IIIb was disconfirmed. Working adolescents were no more optimistic than high school students about their occupational future. Unexpected results on sex differences showed that females were more optimistic than males in respect to the future of their family $(p<0.05)$. Males were more optimistic concerning "physical well-being and appearance" than females at the time of the second measurement $\left(F_{S}=15.63 ; p<0.005\right)$.

\section{Internal-External Control}

On the whole, hypothesis IV was confirmed. In the second measurement the Hauptschule adolescents (after entering employment) described more events as being internally controlled than the Gymnasium students $\left(F_{S}=7.80 ; p<0.01\right)$.

\section{DISCUSSION}

The results of this study clearly demonstrate the effect on future orientation of changes in the objective environment which are accompanied by changes in social roles and personal development.

\section{Effects of Real and Anticipated Changes in One's Life}

These findings are the result of a longitudinal study - the first one (as far as we know) - investigating the effects of life experiences on various aspects of future orientation.

The methodological disadvantages of a longitudinal study (loss of subjects, effects of response bias on account of two measurements) are balanced by the benefits of dealing with information from a real-life experiment - in our case, the "treatment" of leaving school and entering work. As can be seen from our results, this new stage in development brings about significant changes in one's outlook on the future. However, changes in future orientation do not occur only for adolescents who have started to fill a position in the working domain. Adolescents who have to face the end of their status as high school students also undergo changes in the anticipation and evaluation of their future; they have to arrange for a new role as university student or as applicant for a job with all the prominent, more or less predictable, social and personal consequences; this anticipatory socialization brings about changes in future orientation, too.

As we have seen, such changes in future orientation for adolescents occur in different dimensions and content areas, thus partially confirming and partially disconfirming our initial hypotheses. 
The supposition that the future orientation of adolescents grows in regard to extension as well as density (hypotheses la, lla) could be confirmed in the content areas of "persondity" and "occupation" (density and extension). It was found that adolescents included more events in their future orientation two years after the first measurement in these two areas. The predicted increase in extension of future time perspective in the course of two years only took place in the area of "personality". In contrast, there was a decrease in the extension of future orientation in all other areas. This decrease in extension cannot be atuributed to the anticipation of events occurring at a fixed, socially defined, time: the decrease exceeds the time difference of two years between the first and second measurement. (Extension was measured as the difference between the subject's actual age and the estimated age when the future event would materialize.) A possible explanation for this latter result may be that the measurement of extension of future orientation applied here is not adequate, since, by definition, it reflects extremes disproportionately. One indication of this is that Klineberg (1967) and Lessing (1972) found no difference between the two different age groups with regard to extension when a projective test was used. However, the group of older subjects in Klineberg's (1967) study did have a more extended future orientation than the younger subjects when extension was measured by a listing of events ("constrained extension"). The question as to the most adequate operationalization and meas. rement of extension can be clarified only by an exact comparison of both methods of measurement in an empirical investigation. New developments in this area are discussed by Lessing (1972) and O'Rand and Ellis (1974).

The concept of extension, as used by Wallace (1956) and here, is based on the notion that time is linear and the future is perceived as a linear process. This notion is very problematic, as can be seen in our study. As we have shown, a shift in the predominance of concerns has occurred for the adolescents: They anticipate relatively more events in the occupational domain than before, and these events are located in the near future. The less extended length of future time orientation for older adolescents may indicate the increasing importance of problems in the near future. Long-term behavioral plans (which would be indicated by a more extended future orientation) are disregarded in favor of the realization of relatively short-term goals. As can be seen in our study, extension of time perspective into the future has a different psychological meaning depending on which areas of life are concerned. A short extension may indicate a strong concern with actual problems which become increasingly important with age. Entry into work obviously influenced the adolescents' anticipation of personal control of their future. The working adolescents, as compared to the high school students, thought to a greater extent that the materialization of their hopes and fears was within their own control. This difference did not occur at the first measurement (cf. Lamm et al., 1976). 
Probably, independence from the parental family - at least in financial matters - and option between alternative lifestyles increases when one leaves behind the role of a pupil and enters new social roles in the working context. These changes can contribute to an increase in certainty about personal control. In addition, there is a trend on the part of the Gymnasium boys toward enhanced belief in external control. These adolescents stay in a social position which does not expand possibilities for independence and choice in a way that meets their needs.

\section{Effects of Socialization}

Effects of differential changes in different social positions, for working adolescents as compared to high school students could not be demonstrated for the occupational domain of future orientation (cf. hypothesis IIb, IIIb). However, the class-related differences found here are comparable to the results from the first measurement in the original sample $(N=100)$. As Lamm et al. (1976) reported, lower class adolescents (Hauptschule) listed relatively more concerns in the occupational domain than did middle class adolescents (Gymnasium). Our data indicate that this relatively greater concern for the occupational future in lower class as compared to middle class adolescents is quite stable over time. At the first as well as at the second measurement, lower class adolescents structure their future in the occupational domain in more detail than middle class adolescents. This finding indicates that the better schooling of the high-status adolescents does not necessarily help them to structure their future in a more realistic way (cf. Trommsdorff, 1978).

\section{Effects of Sex}

Furthermore, sex-related results - some of which were not explicitly formulated as hypotheses - show that girls had a less extended future orientation in the occupational domain than boys at the first and second measurements. This finding is partly consistent with the findings from the original group of adolescents in the first measurement, where we found a more extended future orientation in the occupational domain for males as compared to females from the Hauptschule (cf. Lamm et al., 1976). However, another difference from the original sample - boys voiced more hopes and fears in the occupational domain than girls - did not occur in the present study. This difference probably disappeared on account of increased experience with new roles. Females as well as males are confronted with the problems of occupational life. Females from the Hauptschule are now (at the second measurement) working for money and/or a career; females of the Gymnasium are facing the point of decision of an oc- 
cupation. In both cases, vecupation-specific problems are of increasing relevance and outweigh the concern with iraditional sex roles, at least for the near future.

However, as regards the distant future, the occupational domain is of less significance for girls than for boys. Whether they are working or not male adolescents extend their occupational concerns more into the future than girls. Real and expected changes in their social position affect boys' hopes and fears, focusing increasingly on less extended developments (which are still significantly more extended into the future than is the case with girls.)

Sex-related differences were also found in the evaluation of the future of family relations. Males in both groups were less optimistic than females at buth testing times. The results indicate that this area of life is not very important for males in their present position. Males tend to structure their future in this domain to a lesser extent than girls. Thus, sex roles determine how the future is perceived at least in the traditionally sex-linked domains of occupation and family.

However, males structure life domains other than the occupational area rather differentially and with greater extension into the future - even more so and increasingly more so - than girls. Males become more preoccupied with their "physical well-being and appearance," while girls become increasingly reluctant to think of their future in this respect. Independent of their social position, females structure their personal future in this respect hardly at all when they become oider (and either have adopted a working position or are preparing for such a change of roles). The data show clearly that the girls' former preoccupalion with their future physical well-being and appearance declines to the advantage of a more differentiated structure of other life domains - "personality and self-actualization" and "occupation". This basic restructuring of one's future after changes in social roles are experienced or anticipated is more characteristic of girts than of boys.

Probably, girls have come to perceive that other factors besides physical attraction are important conditions for one's future development and successful attainment of one's goals.

According to social values, physical attractiveness decreases with age. This may induce girls to avoid the anticipation of a future of their physical appearance; when aging is related to loss of attractiveness, girls prefer to live in the present in this area. This interpretation is supported by our data that males are significantly more optimistic concerning their future in the physical attractiveness domain than girls.

Besides these class- and sex-related effects the present study clearly demonstrates the effects of life changes on several aspects of future orientation. Of course, many questions remain unanswered. There is a need for more intensive research in order to clarify problems of measurement and conceptualization of future orientation and to clarify the genesis and function of future orientation for human behavior. 
As shown here, some aspects of future orientation undergo change after changes in the social environment and related social roles have taken place. Such changes in roles are experienced not only by entering work life but also by mere anticipation of role changes in this area. Future orientation can thus be a product of social conditions. On the other hand, future orientation can play a role in adapting to changes in one's social environments (cf. Atchley, 1975). This "anticipatory-socialization" function of future orientation is part of a complex system of cognitive and motivational processes related to a "naive" theory of behavior in a sequence of time.

\section{References}

Atchley, R. C. (1975). The life course, age grading, and age-linked demands for decision making. In Datan, N., and Ginsberg, L. H. (eds.), Life Span Developmental Psychology: Normative Life Crises, Academic Press, New York.

Barabasz, A. F. (1970). Temporal orientation and academic achievement in college. J. Soc. Psychol. 80:231-232.

Bergius, R. (1957). Formen des Zukunftserlebens, Barth, Munich.

Brannigan, G. G., and Tolor, A. (1971). Sex differences in adaptive styles. J. Genet. Psychol. 119: 143-149.

Cantril, H. (1965). The Pattern of Human Concerns, Rutgers University Press, New Bruns wick, N.J.

Doob, L. W. (1971). Patterning of Time, Yale University Press, New Haven.

Fraisse, P. (1957). Psychologie du temps. Presses Universitaires, Paris.

Heckhausen, H. (1967). The Anatomy of Achievement Motivation, Academic Press, New York.

Jessor, R., Graves, T. D., Hanson, R. C., and Jessor, S. L. (1968). Society, Personality and Deviant Behavior, Holt, Rinchart \& Winston, New York.

Kastenbaum, R. (1961). The dimensions of future time perspective: An experimental analy' sis. J. Gen. Psychol. 65: 203-218.

Klineberg, S. L. (1967). Changes in outlook on the future between childhood and adolescence. J. Personal. Soc. Psychol. 7: 185-193.

Lamm, H., Schmidt, R. W., and Trommsdorff, G. (1976). Sex and social class as determinants of future orientation (time perspective) in adolescents. J. Personal Soc. Psychol. 34: 317-326.

Lehr, U. (1972). Das Problem geschlechtsspezifischer Verhaltensweisen. In Graumann, C. F. (ed.), Handbuch der Psychologie, Vol. 7, No. 2, Hogrefe, Göttingen.

LeShan, L. L. (1952). Tine orientation and social class. J. Abnorm. Soc. Psychol. 47: $589-$ 592.

Lessing, E. E. (1971). Comparative extension of personal and social political future time perspective. Percept. Motor Skills 33: 415-422.

Lessing, E. E. (1972). Extension of personal future time perspective, age and life satisfaction of children and adolescents. Dev. Psychol. 6:457-468.

Lewin, K. (1948). Time perspective and morale. In Lewin, K. (ed.), Resolving Social Conflicts, Harper, New York, pp. 103-124.

Lewin, K. (1951). Field Theory in Social Science. Harper, New York.

Mönks, 1. J. (1967). Sammelreferat: Zeitperspektive als psychologische Variable. Archiv für die Gesamte Psychologie 119: 131-161.

Nuttin, J. (1964). The Future Time Perspective in Human Motivation and Learning: Proccedings of the 17th International Congress of Psychology, North-Holland Publishing Co., Amstcrdim.

O'Rand, A., and Ellis, R. A. (1974). Social class and social time perspective. Soc. Forces $53: 53-62$. 
Raynor, J. O. (1974). Future orjentation in the study of adnevement motivation. In Atkinson, J. W. and Ray'nur, J. O. (eds.), Mothation and Achieventent, Wiley, New York.

Roberts, A. H., and Greene, J. E. (1971). Cross-cultural study of relationship among four dimensions of time perspective. Percept. Motor Skills 33:153-173.

Rotter, J. B. (1966). Generalized expectancies for internal versus external control of reinforcement. Psychol. Monogr. 80(1): Whole No. 609.

Schmidt, R. W. (1973). Soziale Determinanten der Zukunftsperspektive. Eine Untersuchung an berufstätigen Männern und Frauen im Alter zwischen 35 und 45 Jahren. Lnveröfentlichte Diplomurbcit.

Teahan, J. E. (1958). Future time perspective, optimism, and academic achievement. J. Abnorm. Soc. Psychol. 57: 379-380.

Toban, E. V. (1970). Relation between future time perspective, age and militancy. $J$. Genet. Psychol. 116:63-68.

Trommsdorff, G. (1978). Social conditions of future orientation. Paper presented to the European Association of Social Psychology, Weimar.

Trommsdorff, G., and Lamm, H. (1975). An analysis of future orientation and some of its social determinants. In Fraser, I. T., and Lawrence, N. (eds.), The Study of Time, II. Springer, Heidelberg/New York. Pp. 343-361.

Trommsdorff, G., Burger, Ch., Füchsle, T., and Lamm, H. (1978). Erziehung für die Zukunft. Schwann, Dusseldorf.

Wallace, M. (1956). Future time perspective in schizophrenia. J. Abnorm. Soc. Psychol. 52: 240-245.

Weiner, B. (1974). Achievement Motivation and Attribution Theory, General Learning Press, Morristown, N. J.

Winer, B. J. (1971). Statistical Principles in Experimental Design, McGraw-Hill, New York.

Winnubst, J. A. M. (1975). Het westerse tijdssyndroom. Conceptuele integratie en eerste aanzet tot construct validatie van een reeks molai, e ti; dsvariabelen in die psychologie. Swetz \& Zeittinger, Amsterdam.

Zurcher, L. A., Jr., Willis, J. E., Ikard, F. F., and Dohme, J. A. (1967). Dogmatism, future orientation and perception of time. J. Soc. Psychol. 73: 205-209. 